\title{
On the use of a peak deconvolution procedure for the determination of energy barrier to enantiomerization in dynamic chromatography
}

\author{
J. Krupcík ${ }^{*}$, P. Oswald ${ }^{1}$, I. Spánik ${ }^{1}$, P. Májek ${ }^{1}$, M. Bajdichováa ${ }^{1}$ P. Sandra ${ }^{2}$ and D.W. Armstrong ${ }^{3}$ \\ ${ }^{1}$ Department of Analytical Chemistry, Faculty of Chemical Technology, Slovak Technical University, \\ Radlinského 9, 81237 Bratislava, Slovak Republic \\ ${ }^{2}$ Laboratory of Organic Chemistry, University of Gent, Krijgslaan 281 (S4), 9000 Gent, Belgium \\ ${ }^{3}$ Department of Chemistry, University of Missouri-Rolla, Rolla, Missouri, USA
}

\begin{abstract}
Manual or computer assisted peak deconvolution on chromatograms of the racemate of 1-chloro-2,2-dimethylaziridine enantiomers GC was used to determine the peak areas of enantiomers in the racemate prior $\left(A_{A, 0}, A_{B, 0}\right)$ and after the separation $\left(A_{A}, A_{B}\right)$. These peak areas were used in the determination of apparent rate constants and apparent energy barrier to enantiomerization. Comparison of apparent energy barriers determined using deconvolution of chromatograms with data published in literature showed differences within $7 \%$ rel.
\end{abstract}

Key Words. Gas chromatography - peak deconvolution - energy barrier to enantiomerization - 1-chloro-2,2-dimethylaziridine enantiomers.

\section{Introduction}

The term enantiomerization characterizes a process in which the enantiomers undergo inversion of their respective conformations during a chromatographic separation [1]. Enantiomerization of enantiomers $A$ and $B$ can be described by a scheme:

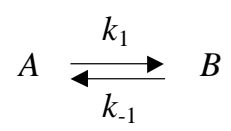

where $k_{1}$ and $k_{-1}$ are the rate constants.

The $A \rightarrow B$ enantiomerization is the first order kinetic reaction which is described by following differential equation:

$$
-\frac{\mathrm{d} c_{A}}{\mathrm{~d} t}=k_{1} \cdot c_{A}-k_{-1} \cdot c_{B}
$$

The $B \rightarrow A$ enantiomerization is described by the similar equation:

$$
-\frac{\mathrm{d} c_{B}}{\mathrm{~d} t}=k_{-1} \cdot c_{B}-k_{1} \cdot c_{A}
$$

where $c$ is concentration of a considered enantiomer and $t$ is time.
Equations 1 and 2 describe interconversion of individual enantiomers in a static system where enantiomers $A$ and $B$ are in a contact. Direct chromatographic separation of enantiomers is, however, a dynamic system, and therefore interconverted enantiomers $A^{*}$ and $B^{*}$ will be separated from the "original ones". A peak cluster composed of a peak of interconverted enantiomers $\left(\mathrm{A}^{*} \mathrm{~B} *\right)$ between the two peaks of enantiomers is formed as a consequence of this separation [2].

Energy barriers to enantiomerization of enantiomers can be determined by several methods. While the isolation of single enantiomers followed by classical racemization kinetics using chiroptical methods is cumbersome and time-consuming, dynamic [1,3-5] and stopped-flow [6,8-10] chromatographic techniques are more straightforward since enantiomers are separated and analyzed on-line, thus requiring only minute amounts of the racemic or enriched mixture of enantiomers. The lower energy barrier to interconversion of enantiomers (around 70-100 $\mathrm{kJ} \mathrm{mol}^{-1}$ ) can be determined by dynamic HPLC (DHPLC) [11]. Higher energy barriers to interconversion of enantiomers (around 70-200 kJ mol-1) can be determined by dynamic gas chromatography (DGC) [9]. DHPLC and DGC has been shown to produce rate constants and energy barriers to enantiomerization in good agreement with those obtained by independent techniques [12] except for the rare case when the stationary phase shows high catalytic activity [13]. Mannschreck with co-workers have used simultaneous photometric ad polarimetric detectors for a

*Correspondence and reprints.

Received September 19, 2000; accepted October 5, 2000. 


\section{Original articles}

deconvolution of chromatograms obtained by the HPLC separation of enantiomers of 1,3,7-trimethylbenzo(c)phenantrene on triacetylcellulose. The peak areas of enantiomers were determined directly from the chromatogram detected by the selective polarimetric detector. Deconvoluted peak areas of enaniomers were used to determine rate constants and energy barrier to enantiomerization $[14,15]$. However, a deconvolution method for the determination of peak areas in a peak cluster obtained by dynamic chromatography with non-selective detection has not been published to our knowledge.

Dynamic enantioselective chromatography is possible to simulate by computer. Simulations of chromatograms are usually performed using discontinuous plate model in an algorithm published by Schurig with co-workers $[1,3]$, which nowadays is available as a SIMUL [21] program. Plate number, retention times, and the hold-up time of the column are determined experimentally. These figures together with rate constants for the reaction in the mobile and stationary phases, $k^{m}$ and $k^{s}$, are used as input parameters. The program is iterative where the rate constants are changed until the simulated and experimental chromatograms show the best correspondence. A general observation is that the height of the second enantiomer peak in the simulated chromatograms is slightly lower than expected. This might be caused by the different number of theoretical plates found for the first and second enantiomers in the experimental chromatograms $[3,11,16]$.

The aim of this paper is to utilize a peak deconvolution on experimental chromatograms obtained by DGC separation of 1-chloro-2,2-dimethylaziridine enantiomers for the determination of rate constants and energy barriers to enantiomerization.

\section{Theoretical}

The direct chromatographic separation of a racemic or enriched mixture of thermolabile enantiomers is known as a dynamic enantioselective chromatography. This process has been studied by a peak deconvolution procedure $[14,15]$ or more often by computer simulation [1,3]. Peak areas of enantiomers determined by these methods were used to calculate apparent rate constants, which are weighted means of the different enantiomerization rates in the mobile and the stationary phase [3]. The rate constant $\left(k_{1}^{\text {app }}\right)$ of enantiomerization $A$ to $B$, can be calculated from peak areas using following equation [9]:

$$
k_{1}^{\mathrm{app}}=\frac{1}{2 t} \ln \frac{A_{A, 0}}{2 A_{A}-A_{A, 0}} .
$$

A similar equation can be used for the calculation of apparent rate constant $\left(k_{-1}^{\mathrm{app}}\right)$ of enantiomerization $B$ to $A$ :

$$
k_{-1}^{\text {app }}=\frac{1}{2 t} \ln \frac{A_{B, 0}}{2 A_{B}-A_{B, 0}}
$$

where $A_{0}$ and $A$ are the peak areas of the enantiomer prior to and after the chromatographic separation, respectively. If $k^{m}$ values can be found by an independent technique, $k^{s}$ are obtained from the determined $k^{\text {app }}$ values. $k^{s}$ are lower than $k^{m}$ since the energy barrier to enantiomerization in the stationary phase is usually higher than in the mobile phase $[16,17]$.

Enantiomerization rate constants in chiral stationary phase $\left(k_{1}^{s,} k_{-1}^{s}\right)$ can be found from apparent $\left(k_{1}^{\text {app }}, k_{-1}^{\text {app }}\right)$ and mobile phase $\left(k^{m}=k_{1}^{m}=k_{-1}^{m}\right)$ rate constants and retention factors of enantiomers $\mathrm{A}\left(k_{A}\right)$ and $\mathrm{B}\left(k_{B}\right)$ using following equations [3]:

$$
k_{1}^{s}=\frac{k_{1}^{\mathrm{app}}\left(1+k_{A}\right)-k^{m}}{k_{A}}
$$

and

$$
k_{-1}^{s}=\frac{k_{-1}^{\mathrm{app}}\left(1+k_{B}\right)-k^{m}}{k_{B}} .
$$

The temperature $(T)$, the enantiomerization time $(t)$ and the measured peak areas of the enantiomer prior $\left(A_{A, 0}\right)$ and after $\left(A_{A}\right)$ enantiomerization are required for the calculation of energy barrier to enantiomerization.

The energy barriers to enantiomerization $\Delta G_{A \rightarrow B}^{\mathrm{app}}$ and $\Delta G_{B \rightarrow A}^{\mathrm{app}}$ are accessible from the rate constants $k_{l}^{\text {app }}$ and $k_{-1}^{\text {app }}$ using the Eyring equation:

$$
\begin{aligned}
& k_{1}^{\mathrm{app}}=\left(k_{b} T / h\right) e^{-\Delta G_{A}^{\mathrm{app}} B^{\mathrm{R} T} .} . \\
& k_{-1}^{\mathrm{app}}=\left(k_{b} T / h\right) e^{-\Delta G_{b \rightarrow A^{\mathrm{app}} T} .}
\end{aligned}
$$

where $k_{b}$ is Boltzmann constant, $T$ is temperature in $K, h$ is Planck's constant and $R$ is universal gas constant [18,19].

\section{Materials and methods}

\section{Instrumentation}

A gas chromatograph HP 5890 series II (Hewlett-Packard, Avondale, USA) equipped with flame ionization detector (FID) and split/split-less injection port have been used. Hydrogen of $99,99 \%$ purity with $40 \mathrm{~cm} / \mathrm{s}$ velocity was used as a carrier gas. 99,999\% nitrogen was used as a make-up gas to FID. Signal of FID was monitored by a HP 3396 integrator and via a Peak 96 software transmitted to a IBM compatible PC 386 were it was evaluated by a HP 3365 series II Chemstation software (all products were purchased from Hewlett-Packard, Avondale, USA).

The separation of 1-chloro-2,2-dimethylaziridine enantiomers was performed under isothermal conditions with $10{ }^{\circ} \mathrm{C}$ step in the temperature intervals $80-110{ }^{\circ} \mathrm{C}$ (with the column A) and $70-90{ }^{\circ} \mathrm{C}$ (with the column B). 


\section{Original articles}

\section{Capillary columns}

Following fused silica capillary columns were used for DGC separation of 1-chloro-2,2-dimethtyl aziridine enantiomers:

Column A: $30 \mathrm{~m}$ capillary column with $0.25 \mathrm{~mm}$ i.d. coated with $0.125 \mu \mathrm{m}$ film thickness of heptakis(2,6-di-Opentyl-3-trifluoroacetyl)- $\beta$-cyclodextrin (Chiral Dex B-TA).

Column B: $30 \mathrm{~m}$ capillary column with $0.25 \mathrm{~mm}$ i.d. coated with $0.125 \mu \mathrm{m}$ film thickness of octakis(2,6-di-Opentyl-3-trifluoroacetyl)- $\gamma$-cyclodextrin (Chiral Dex G-TA).

Capillary columns Chiral Dex B-TA and Chiral Dex GTA were prepared in the Department of Chemistry, University of Missouri-Rolla, Rolla, Missouri, USA.

The columns also can be obtained from Advances Separation Technologies, Inc. (Whippany, NJ, USA)

\section{Sample}

1-chloro-2,2-dimethylaziridine was prepared from 2-methyl2-amino-1-propanol and $\mathrm{NaClO}$ using procedures described by Coleman [22] and Graefe and Meyer [23].

2,2-dimethylaziridine was prepared from 2-methyl-2amino-1-propanol according to procedures described by Cairns [24] and Cambel with co-workers [25].

\section{Theoretical calculations}

The standard semiempirical AM1 method of quantum chemistry (AMPAC program package) [26,27] was used to find the optimal geometry (Fig. 1) and to calculate rotational energy barriers $\left(\Delta E_{\mathrm{rot}}\right)$ of 1-chloro 2,2-dimethylziridine. All calculations were performed in higher precision (keyword PRECISE) using the Davidon-Fletcher-Powell optimisation procedure $[28,29]$. As the reaction coordinate was defined dihedral angle $\{\Psi(\mathrm{Cl}-\mathrm{N}-\mathrm{C} 2-\mathrm{C} 3)\}$. On the figure 2 three rotational barries $\left(\Delta E_{\text {rot }}\right)$ for chlorine atoms at 180 degrees $108.4 \mathrm{~kJ} \mathrm{~mol}^{-1} ; 60$ and 300 degrees $136.8 \mathrm{~kJ} \mathrm{~mol}^{-1}$ and 0 and 360 degrees $342.6 \mathrm{~kJ} \mathrm{~mol}^{-1}$ are depicted. The value $\Delta E_{\mathrm{rot}}=108.4 \mathrm{~kJ} \mathrm{~mol}^{-1}$ is a barrier to enantiomerization of 1-chloro 2,2-dimethylziridine during its chromatographic separation (the lone-pair rotate near hydrogen atoms bonded on atom $\mathrm{C} 3$ ). From figure 2 is evident that the electron lonepair of the nitrogen atom in the molecule is responsible that the hindered rotation has the high value $\Delta E_{\text {rot }}=$ $342.6 \mathrm{~kJ} \mathrm{~mol}^{-1}$. Data showed in table I show that the theoretically calculated energy rotational barrier $\Delta E_{\text {rot }}$ $=108.4 \mathrm{~kJ} \mathrm{~mol}^{-1}$ is in a good agreement with the experimental values obtained by DGC.

\section{Results and discussion}

Chromatograms obtained by the gas chromatographic separation of 1-chloro-2,2-dimethylaziridine on heptakis(2,6-diO-pentyl-3-O-trifluoroacetyl)- $\beta$-cyclodextrin and octakis(2,6-di-O-pentyl-3-O-trifluoroacetyl)- $\gamma$-cyclodextrin at various
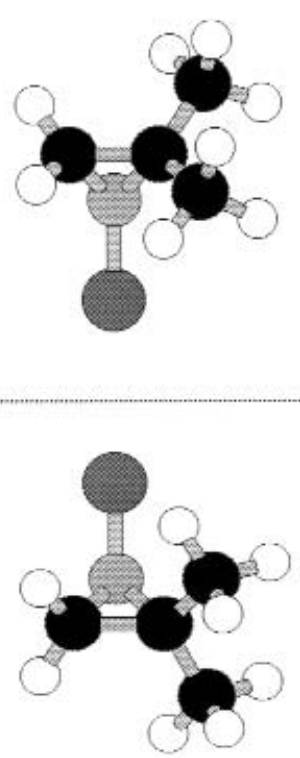

Figure 1. Optimum conformations of 1-chloro-2,2-dimethylaziridine enantiomers. - carbon, $\bigcirc$ - nitrogen, $\bigcirc$ - hydrogen, $\bigcirc$ chlorine.

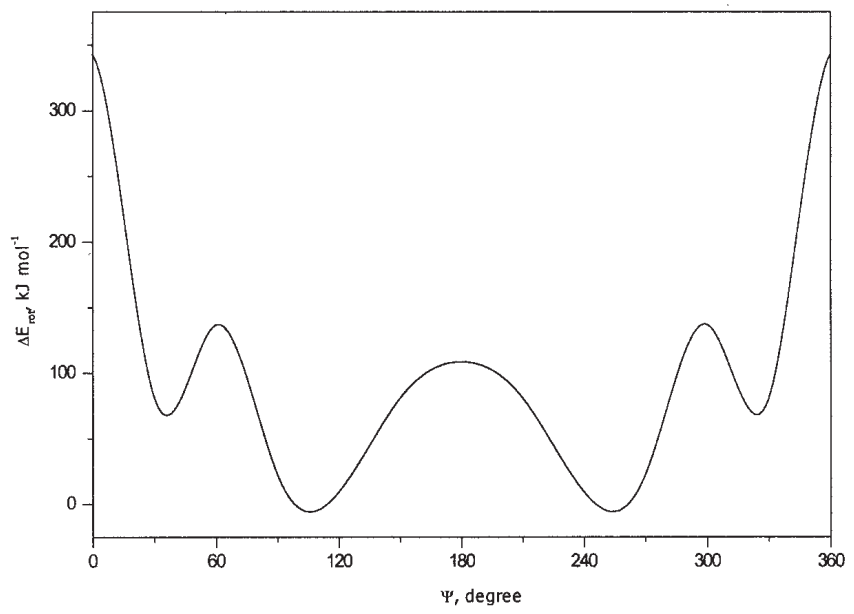

Figure 2. Reaction coordinate $\left(\Delta E_{\text {rot }}\right)$ of 1-chloro-2,2-dimethylaziridine for dihedral angle $(\psi)$.

temperatures were used for the determination of enantiomerization barrier using a peak deconvolution method. The following assumptions were considered prior to determination of enantiomer peak areas by a peak deconvolution method:

a) Enantiomer peak areas prior to separation of a racemic mixture can be determined from overall peak area of a peak cluster registered on an experimental chromatogram:

$$
A_{A, 0}=A_{B, 0}=\left(A_{A}+A_{B}+A_{A * B *}\right) / 2 .
$$

b) Response of a chromatographic detector for enantiomers $(A, B)$ and products of enantiomerization (enantiomers arose during enantiomerization denoted as $\left.A * B^{*}\right)$ is equal. 


\section{Original articles}

Table I. Energy barriers to enantiomerization found for 1-chloro-2,2-dimethylaziridine by various methods.

\begin{tabular}{|c|c|c|c|c|}
\hline \multirow[t]{2}{*}{ Method } & \multirow[t]{2}{*}{ Temperature, $K$} & \multicolumn{2}{|c|}{ Energy barrier, $\mathrm{kJ} \mathrm{mol}^{-1}$} & \multirow[t]{2}{*}{ Ref. } \\
\hline & & $\begin{array}{c}\text { First peak, } A \\
\quad \mathrm{~A} \rightarrow \mathrm{B}\end{array}$ & $\begin{array}{c}\text { Second peak, } \mathrm{B} \\
\mathrm{B} \rightarrow \mathrm{A}\end{array}$ & \\
\hline DGC, Chiral Dex B-TA & 363.15 & 112.2 & 112.5 & \\
\hline DGC, Chiral Dex G-TA & 363.15 & 109.6 & 109.1 & \\
\hline MDGC & 351.15 & \multicolumn{2}{|c|}{$112.1 \pm 0.4$} & [9] \\
\hline Complexation, DGC & 333.15 & \multicolumn{2}{|c|}{$104.9 \pm 0.6$} & [1] \\
\hline Classical kinetics & 338.45 & \multicolumn{2}{|c|}{$115.5 \pm 1.2$} & [13] \\
\hline
\end{tabular}

c) Enantiomers arose during enantiomerization are eluted in a broad peak between the peaks of enantiomers.

d) Peaks of enantiomers (A, B) and interconverted enantiomers $(\mathrm{A} * \mathrm{~B} *)$ are symmetrical.

Peak area of enantiomers on chromatograms were determined by following manual deconvolution procedure:

1) The chromatograms were enlarged 3 -fold using a copy machine.

2) The weight proportional to overall peak area $\left(A_{A}+B_{B}+A_{A^{*} B^{*}}\right)$ was obtained by weighing a peak cluster obtained by cutting the appropriate part of the chromatogram.

3) The weight proportional to peak areas of enantiomers prior to chromatographic separation $\left(A_{A, 0}\right.$ and $\left.A_{B, 0}\right)$ were calculated from equation 8 .

4) The weight proportional to the peak area of enantiomer $A$ and $B$ after the chromatographic separation $\left(A_{A}, A_{B}\right)$ was determined by cutting out the peak cluster with the modified baseline as indicated in figure $3 \mathrm{~A}$ or figure $4 \mathrm{~A}$ and weighing the corresponding cuts. The dotted lines in figures $3 \mathrm{~A}$ and $4 \mathrm{~A}$ were constructed using the following assumptions:

- the baseline width of the intermediate peak, which belongs to products of enantiomerization and which do not interfere with enantiomers during their migration through the column, is equal to the base peak cluster width;

- the height of the intermediate peak is approximately given by the height of the plateau between the peaks of enantiomers.

Program built in Origin [30] was used for computer assisted deconvolution of peak clusters on figure $3 \mathrm{~B}$ and figure $4 \mathrm{~B}$. Since peaks on the chromatograms were almost symmetrical, a Gaussian function was used in the deconvolution procedure to describe a peak design. Dashed and dotted lines in figure $3 \mathrm{~B}$ and figure $4 \mathrm{~B}$ show part of the experimental chromatogram (a peak cluster) and peaks obtained by computer assisted deconvolution of the peak cluster for original $(A$ and $B)$ and interconverted $(A B)$ enantiomers, respectively. The solid line shows the peak cluster that arose by summing the deconvoluted peaks. Apparent rate constants for both
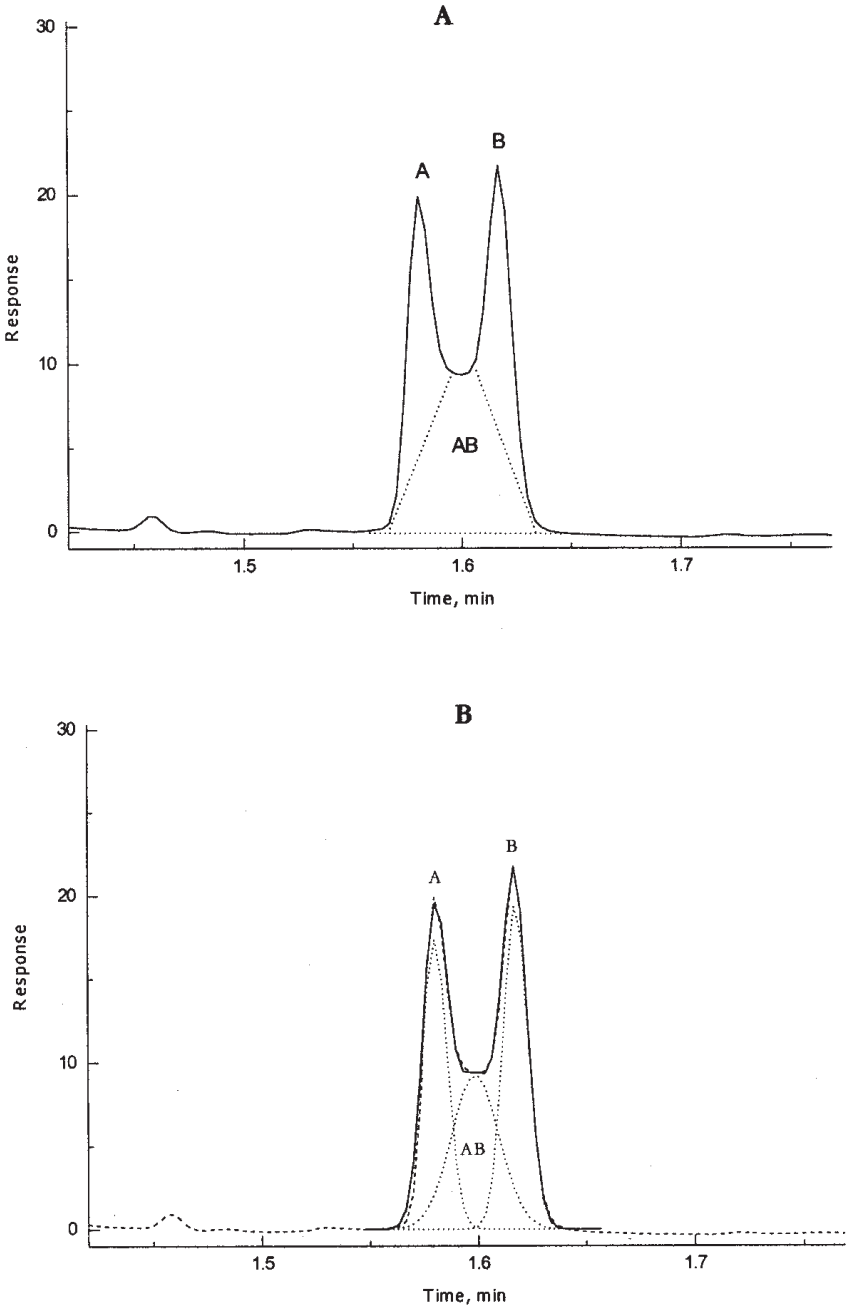

Figure 3. Schematic of manual (A) and computer assisted (B) deconvolution a of chromatogram obtained by the separation of 1chloro-2,2-dimethylaziridine by gas chromatography on Chiral Dex G-TA capillary column at $110^{\circ} \mathrm{C}$.

enantiomers $\left(k_{A \rightarrow B}^{\text {app }}\right.$ and $\left.k_{B \rightarrow A}^{\text {app }}\right)$ were calculated from the corresponding peak areas using equations 3 and 4 . Energy barriers to enantiomerization $\left(G_{A \rightarrow B}^{\text {app }}\right.$ and $\left.G_{B \rightarrow A}^{\text {app }}\right)$ calculated using Equations 6 and 7 for 1-chloro-2,2-dimethylaziridine enantiomers separated on Chiral Dex B-TA and Chiral Dex G-TA 

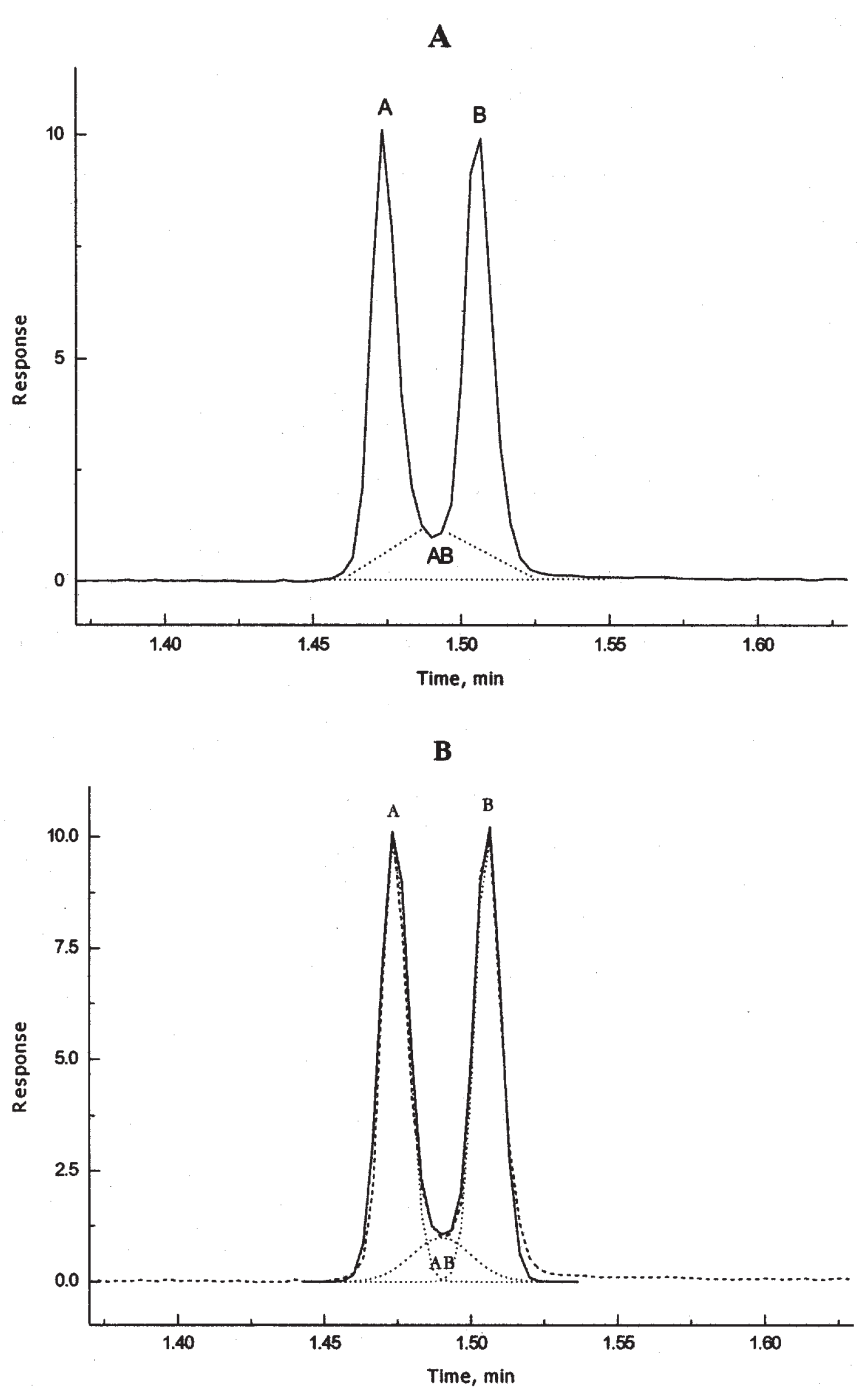

Figure 4. Schematic of manual (A) and computer assisted (B) deconvolution a of chromatogram obtained by the separation of 1chloro-2,2-dimethylaziridine by gas chromatography on Chiral Dex B-TA capillary column at $80^{\circ} \mathrm{C}$.

capillary columns at $90{ }^{\circ} \mathrm{C}$ are depicted in table I together with some published data. In spite of the fact that the energy barriers listed in Table I were measured at various temperatures and they are not fully homogenous (e.g. published [1,9] $\Delta G^{\#}$ and considered $G_{A \rightarrow B}^{\text {app }}$ and $G_{B \rightarrow A}^{\text {app }}$ data) comparison of the data shows that the type of chiral selector influences the value of the energy barrier to enantiomerization. Results in Table I show that enantiomerization energy barriers $\left(G_{A \rightarrow B}^{\mathrm{app}}\right.$ and $\left.G_{B \rightarrow A}^{\mathrm{app}}\right)$ are somewhat different and they are higher for second eluted enantiomer $\left(G_{B \rightarrow A}^{\text {app }}\right.$ $\left.>G_{B \rightarrow A}^{\mathrm{app}}\right)$ which corresponds to the stronger interaction of the chiral selector with the second eleuted enantiomer.

\section{Acknowledgements}

The authors would like to acknowledge the Slovak Ministry of Education for a grant GAV 1/6104/99 and Agency for
International Science and Technology Cooperation in Slovaquia for a Grant n 002-98.

\section{References}

1. Bürkle, W.; Karfunkel, H.; Schurig, V. J. Chromatogr. 1984, 288, 1-14.

2. Stephan, B.; Zinner, H.; Kastner, F. Mannschreck, A. Chimia 1990, 44, 336-338.

3. Jung, M., Schurig, V. J. Am. Chem. Soc. 1992, 114, 529-534.

4. Mannschreck, A.; Zinner, H.; Pustet, N. Chimia 1989, 43, 165166.

5. Veciana, J.; Crespo, M.I. Angew. Chem. 1991, 30, 85-88.

6. Weseloh, G.; Wolf, C.; König, W.A. Angew. Chem. 1995, 107, 1771-1772.

7. Schurig, V.; Glausch, A.; Fluck, M. Tetr. Asymm. 1995, 6, 2161-2164.

8. Weseloh, G.; Wolf, C.; König, W.A. Chirality 1996, 8, 441445.

9. Reich, S.; Schurig, V. In P.Sandra, A.J.Rackstraw, Eds, Proceedings of the $20^{\text {th }}$ International Symposium on Capillary Chromatography, I.O.P.M.S. vzw., Kortrijk, Belgium, 1998, J.13.

10. Schurig, V.; Reich, S. Chirality 1998, 10, 425-429.

11. J.Oxelbark, J.; Allenmark, S. J. Org. Chem. 1999, 64, 14831486.

12. Gasparrini, F.; Lunazzi, L.; Misiti, D; Villani, C. Acc. Chem. Res. 1995, 28,163-170.

13. Schurig, V.; Leyrer, U. Tetrahedron: Asymmetry 1990, 1, 865868.

14. Mannschreck, A.; Andert, D.; Eiglsperger, E.; Gmahl, E.; Buchner, H. Chromatographia 1988, 25, 182-188.

15. Mannschreck, A.; Kiessel, L. Chromatographia 1989, 28, 263266.

16. Oxelbark, J.; Allenmark, S. J. Chem. Soc. Perkin Trans. 1999, 2, 1587-1589.

17. Pirkle, W. H.; Brice, L. J.; S.Widlanski, T.; Roestamadji, J. Tetrahedron: Asymmetry 1996, 7, 2173-2176.

18. Charlton, J.L.; Oleschuk, C.J.; Chee, G.-L. J. Org. Chem. 1996, 61, 3452-3457.

19. Moore, W.J. Physical Chemistry; Fourth Edition, Englewood Cliffs, New Jersey, USA,: Prentice-Hall, Inc., 1972, Chapter 9.29 .

20. Felinger, A. Data Analysis and Signal Processing in Chromatography. Data Handling in Science and Technology; Paris: Elsevier, Vol. 21, 1998.

21. Jung, M. QCPE Bull.1992, 12, 52.

22. Coleman, G.H. J. Am. Chem. Soc. 1933, 55, 3001-3005.

23. Graefe, A.F.; Meyer, R.E. J. Am. Chem. Soc. 1958, 80, 3949.

24. Cairns, T.L. J. Am. Chem. Soc. 1941, 63, 871-872.

25. Campbell, K.N.; Sommers, A.H.; Campbell, B.K. Org. Synth. Coll.; New York: John Wiley \& Sons Inc., 1967, Vol. III., p 148.

26. Dewar, M.J.S.; Thiel, W. AMPAC. Austin Method 1 Package. Austin, TX: University of Texas, 1986.

27. Dewar, M.J.S.; Zoebisch, E.G.; Healy, E.F.; Stewart, J.J.P. J. Am. Chem. Soc. 1985, 107, 3902-3909.

28. Fletcher, R.; Powell, M.J.D. Comput. J. 1963, 6, 163-168.

29. Davidon, W.C. Comput. J. 1968, 10, 406-410.

30. Microcal $^{\mathrm{TM}}$ Origin $^{\mathrm{TM}}$ Version 4.10, Microcal Software, One Roundhouse Plaza, Northampton, MA, 01060 USA. 